\title{
Effectiveness of sulforaphane as a radiosensitizer for murine osteosarcoma cells
}

\author{
YASUSHI SAWAI ${ }^{1,2}$, HIROAKI MURATA ${ }^{1,3}$, MOTOYUKI HORII $^{1}$, KAZUTAKA KOTO $^{1,2}$, \\ TAKAAKI MATSUI ${ }^{1}$, NAOYUKI HORIE $^{1}$, YOSHIRO TSUJI $^{1}$, EISHI ASHIHARA ${ }^{4}$, \\ TAIRA MAEKAWA ${ }^{4}$, TOSHIKAZU KUBO ${ }^{1}$ and SHINJI FUSHIKI ${ }^{2}$ \\ Departments of ${ }^{1}$ Orthopaedics and ${ }^{2}$ Pathology and Applied Neurobiology, Graduate School of Medical Science, \\ Kyoto Prefectural University of Medicine, Kamigyo-ku, Kyoto 602-8566; ${ }^{3}$ Department of Orthopaedics, \\ Matsushita Memorial Hospital, Moriguchi City, Osaka 570-8540; ${ }^{4}$ Department of Transfusion Medicine \\ and Cell Therapy, Kyoto University Hospital, Shogoin, Sakyo-ku, Kyoto 606-8507, Japan
}

Received October 8, 2012; Accepted November 19, 2012

DOI: 10.3892/or.2012.2195

\begin{abstract}
Sulforaphane (SFN), a naturally occurring member of the isothiocyanate family, is effective against various types of malignant tumor cells. We studied whether the combination of SFN and radiation would be more effective against osteosarcoma cells when compared to these treatments alone. LM8 murine osteosarcoma cells were cultured with various concentrations of SFN for $24 \mathrm{~h}$ and/or $2 \mathrm{~Gy}$ X-irradiation. The effects of individual and combination treatments on the number of cells, the cell cycle, cell proliferation-related factors and apoptosis were analyzed. The combination of SFN plus radiation had significantly greater antitumor effects than either treatment alone. Exposure to SFN increased the population of cells in the $G_{2} / M$ phase. Combination treatment resulted in a higher percentage of cells being in sub- $\mathrm{G}_{1}$ than did SFN alone. In addition, the combination of SFN and radiation effectively induced nuclear fragmentation and apoptotic bodies, as shown by DAPI staining. The combination of SFN and $2 \mathrm{~Gy}$ radiation increased the cleavage and activation of caspase- 3 compared with SFN or radiation alone, as shown by western blotting. Although radiation alone increased the phosphorylation of ERK and Akt proteins, the combination of SFN and radiation induced suppression of ERK and Akt phosphorylation when compared with radiation alone. We found that SFN enhanced the radiosensitivity of LM8 murine osteosarcoma cells by inducing apoptosis through $\mathrm{G}_{2} / \mathrm{M}$-phase arrest and by inhibiting ERK and Akt activation. These findings suggest that SFN can be used as a radiosensitizer for osteosarcomas.
\end{abstract}

Correspondence to: Dr Hiroaki Murata, Department of Orthopaedics, Graduate School of Medical Science, Kyoto Prefectural University of Medicine, 465 Kawaramachi-Hirokoji, Kamigyo-ku, Kyoto 602-8566, Japan

E-mail: murah@koto.kpu-m.ac.jp

Key words: sulforaphane, radiation, osteosarcoma, apoptosis, mitogen-activated protein kinase, phosphatidylinositol-3 kinase, combination therapy, radiosensitizer

\section{Introduction}

Osteosarcoma is the most common primary malignant bone tumor in children and adolescents. Standard treatment consists of multi-agent neoadjuvant chemotherapy, radical excision of the tumor and adjuvant chemotherapy $(1,2)$. However, many patients still succumb to the disease as a result of tumor metastasis and relapse $(3,4)$. The chemoresistance of tumor cells is one of the most prevalent causes of therapeutic failure $(5,6)$. Although patients with chemoresistant cells require palliative treatment such as radiotherapy, osteosarcomas are considered to be radioresistant tumors $(7,8)$, necessitating the combination of chemotherapy and radiotherapy for these patients $(8,9)$.

In general, tumor cells are the most radiosensitive during $\mathrm{G}_{2} / \mathrm{M}$ phase of the cell cycle and the most radioresistant in $\mathrm{S}$ phase $(10,11)$. Radiotherapy has been shown to activate the mitogen-activated protein kinase (MAPK) and phosphatidylinositol-3 kinase (PI3K)/Akt pathways, which regulate cell proliferation and apoptosis. Inhibition of these pathways has been reported to enhance radiosensitivity of cells $(12,13)$.

New osteosarcoma treatment regimens have been investigated, including many clinical trials of novel agents, among which is sulforaphane (SFN) (14), a naturally occurring member of the isothiocyanate family produced by cruciferous vegetables such as broccoli (15). SFN has been shown to suppress the growth of T-cell leukemia, colon, breast and prostate cancer cells in vitro by inhibiting cell cycle progression (16-20) and/or causing apoptosis $(17,18)$. We previously reported that SFN inhibited the proliferation of cultured murine osteosarcoma LM8 cells i) by inducing $\mathrm{G}_{2} / \mathrm{M}$ phase arrest, as shown by the appearance of cells with sub- $\mathrm{G}_{1}$ DNA content; and ii) by inducing apoptosis, as shown by the cleavage and activation of caspase-3 (21). In addition, SFN inhibited the activation of the PI3K/Akt and MAPK pathways in pancreatic and prostate cancer cells $(22,23)$.

Our findings that SFN induced G2/M-phase arrest and inhibited the PI3K/Akt and MAPK pathways, suggest that SFN may enhance the radiosensitivity of LM8 cells. Moreover, the combination of SFN and radiotherapy may 
further inhibit cell growth, thereby allowing a decrease in the doses of both drug and irradiation to safer levels than when used alone, ensuring a lower incidence and grade of side effects. Although SFN has been found to promote the radiosensitization of cancer cells $(24,25)$, the combined effects of SFN and radiation in osteosarcoma cells have not been studied. We, therefore, analyzed the effects of SFN and radiation on LM8 cells, including their effects on cell cycle, the inhibition of the MAPK and PI3K/Akt pathways and the induction of apoptosis.

\section{Materials and methods}

Reagents. Sulforaphane (SFN) was purchased from LKT Laboratories, Inc. (St. Paul, MN, USA), and was dissolved in dimethyl sulfoxide (DMSO); equivalent volumes of DMSO were used as controls. The maximum percentage of DMSO in the assays was $0.1 \%$.

$X$-ray irradiation. Cultured cells were irradiated with 2 Gy X-rays using Softex M-150WE (Softex Co., Ltd., Tokyo, Japan). The cells were placed $1 \mathrm{~cm}$ from the focus and the irradiation rate was $0.5 \mathrm{~Gy} / \mathrm{min}$ in air.

Cell culture. The LM8 murine osteosarcoma cell line was established from the murine Dunn osteosarcoma cell line and exhibit high metastatic potential to the lungs (27). LM8 cells were cultured in Dulbecco's modified Eagle's medium (DMEM) with $10 \%$ fetal calf serum (FCS) containing antibiotics (100 U/ml penicillin $\mathrm{G}, 100 \mathrm{mg} / \mathrm{ml}$ streptomycin) and incubated at $37^{\circ} \mathrm{C}$ in a humidified atmosphere of $5 \% \mathrm{CO}_{2}$.

\section{Concurrent exposure to SFN and radiation}

Effects on cell growth. LM8 cells were cultivated in 6-well plates at $2 \times 10^{4}$ cells/well in $2 \mathrm{ml}$ medium for $24 \mathrm{~h}$, followed by incubation with various concentrations of SFN for $24 \mathrm{~h}$ and/or $\mathrm{X}$-irradiation at $2 \mathrm{~Gy}$. After 24 or $48 \mathrm{~h}$, the number of viable cells was counted using a trypan blue dye exclusion test. The data are presented as the means \pm standard deviation (SD) of at least three independent experiments.

Analysis of cell cycle progression. To assess the effects of SFN alone, radiation alone or the two treatments together on the cell cycle, LM8 cells were cultivated in 6-well plates at $2 \times 10^{4}$ cells/well and exposed to various doses of SFN and/or irradiation for $24 \mathrm{~h}$. After $48 \mathrm{~h}$, the cells were stained with propidium iodide (Sigma Aldrich, St. Louis, MO, USA), and the stained nuclei were analyzed by flow cytometry (FACSCalibur, Becton-Dickinson, Franklin Lakes, NJ, USA). DNA histograms were created using CellQuest software for Apple Macintosh (Becton-Dickinson). For all assays 10,000 events were counted, with each assay performed in triplicate.

Western blot analysis. LM8 cells were plated in 6-well culture plates at $2.0 \times 10^{4}$ cells/well and incubated for $24 \mathrm{~h}$, followed by incubation with $20 \mu \mathrm{M} \mathrm{SFN}$ for $24 \mathrm{~h}$ and/or radiation at 2 Gy. After 1 and $48 \mathrm{~h}$, the cells were washed twice with PBS and lysed with RIPA buffer [20 mM Tris- $\mathrm{HCl}(\mathrm{pH} 7.4)$, $150 \mathrm{mM} \mathrm{NaCl}, 0.1 \%$ SDS, $1 \%$ Nonidet P-40, $0.5 \%$ sodium deoxycholate, $40 \mathrm{mM} \mathrm{NaF}$, and protease inhibitor cocktail
(Sigma Aldrich)]. The lysates were centrifuged at 15,000 rpm for $20 \mathrm{~min}$; the supernatant lysate was incubated in sample buffer [0.0625 M Tris-HCl (pH 6.8), 2\% SDS, 5\% glycerol, $5 \% 2-\mathrm{ME}]$ at $95^{\circ} \mathrm{C}$ for $5 \mathrm{~min}$; and the samples were separated by sodium dodecyl sulfate-polyacrylamide gel electrophoresis (SDS-PAGE), followed by electroblotting onto nitrocellulose membranes (Amersham Biosciences, Tokyo, Japan). The membranes were incubated in 5\% (wt/vol) non-fat dry milk in Tris-buffered saline with Tween 20 (TBST) $[25 \mathrm{mM}$ Tris $\mathrm{HCl}$ (pH 7.8), $140 \mathrm{mM} \mathrm{NaCl}, 0.1 \%$ (vol/vol) Tween 20] and incubated overnight with the following antibodies (each from Cell Signaling Technology, Beverly, MA, USA, and diluted 1:1,000 in TBST): extracellular signal-regulated kinase (ERK1/2), phosphorylated ERK1/2 (pERK1/2), Akt, phosphorylated Akt (p-Akt), caspase-3, cleaved caspase-3 and GAPDH. The membranes were washed thoroughly with TBST, incubated for $1 \mathrm{~h}$ with horseradish peroxidase-conjugated anti-mouse or -rabbit IgG (Santa Cruz Biotechnology, Santa Cruz, CA, USA), diluted 1:5,000 in TBST, and developed with enhanced chemiluminescence kits (Amersham Biosciences).

Analysis of nuclear morphology. LM8 cells treated with SFN and/or radiation under appropriate conditions were cultured for $48 \mathrm{~h}$, fixed with $2 \%$ paraformaldehyde in PBS for $10 \mathrm{~min}$, and stained with DAPI (4',6-diamidino-2-phenylindole dihydrochloride) (Nacalai Tesque, Inc., Kyoto, Japan) at $4^{\circ} \mathrm{C}$ in the dark. For fluorescence microscopy, cells were cytospun onto slides and examined using a fluorescence microscope Eclipse 1000 (Nikon, Tokyo, Japan) with UV illumination. Apoptotic cells were identified on the basis of characteristic changes, including nuclear condensation, fragmentation and apoptotic bodies.

Statistical analysis. All data are represented as the means \pm SD. Statistical significance was determined using Student's t-tests. $\mathrm{P}<0.05$ was considered to indicate a statistically significant result.

\section{Results}

Growth inhibitory effects of combination therapy in murine osteosarcoma LM8 cells. The combination of SFN and radiation treatment produced significantly greater antitumor effects on the LM8 osteosarcoma cells than either treatment alone (Fig. 1). Stronger combined effects were observed $48 \mathrm{~h}$ after treatment of SFN and radiation than effects obtained after $24 \mathrm{~h}$.

Combined effects of SFN and radiation on the distribution of the cell cycle. To determine the effects of SFN and radiation on cell cycle progression in LM8 cells, the DNA content of their nuclei was assessed by flow cytometry. Exposure to SFN for $72 \mathrm{~h}$ dose-dependently increased the population of cells in the $\mathrm{G}_{2} / \mathrm{M}$ phase (Fig. 2A). Following exposure to SFN plus $2 \mathrm{~Gy}$ radiation, the numbers of cells in the $\mathrm{G}_{2} / \mathrm{M}$ phase (Fig. 2A) and in sub- $G_{1}$ (Fig. 2B) were greater than these values after exposure to SFN alone.

Combined effects of SFN and radiation on apoptosis of LM8 cells. Nuclear fragmentation and apoptotic bodies characteristic of apoptosis were observed with DAPI staining in LM8 


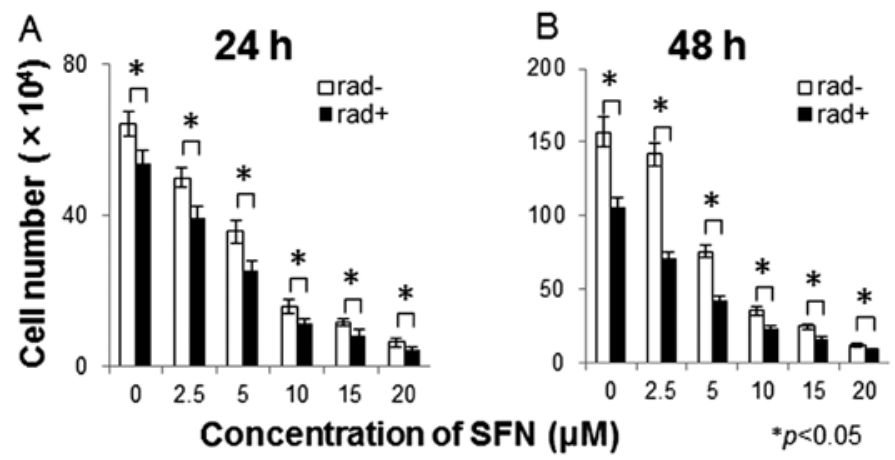

Figure 1. Effect of combination therapy on the growth of murine osteosarcoma LM8 cells. Twenty-four hours after seeding, LM8 cells were incubated with 0 , $2.5,5,10,15$ and $20 \mu \mathrm{M} \mathrm{SFN}$ for $24 \mathrm{~h}$, followed by exposure to $2 \mathrm{~Gy}$ X-irradiation (black bars, rad+) or its absence (white bars, rad-). The numbers of viable cells were counted after (A) $24 \mathrm{~h}$ and (B) $48 \mathrm{~h}$ using a trypan blue dye exclusion test. Shown are the means $\pm \mathrm{SD}$ (bars) of at least three independent experiments.

A

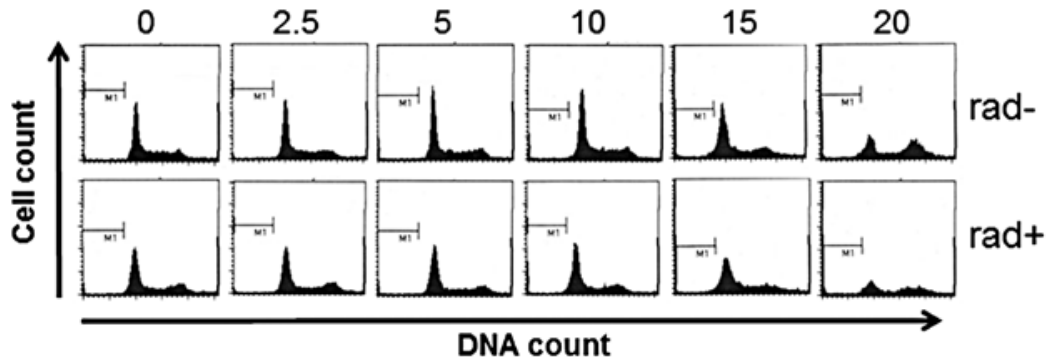

B

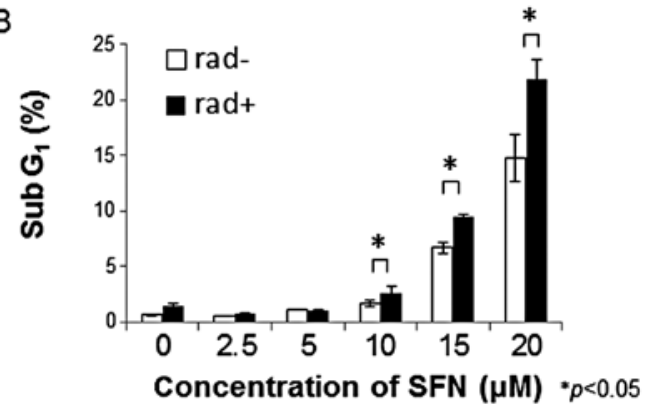

Figure 2. Effects of SFN plus radiation on the cell cycle and the proportion of cells in sub- $\mathrm{G}_{1}$. (A) Cell cycle analysis following combined treatment with SFN plus radiation. Twenty-four hours after seeding, LM8 cells were treated with $0,2.5,5,10,15$ and $20 \mu \mathrm{M} \mathrm{SFN}$ for $24 \mathrm{~h}$, followed by treatment with (rad+) or without (rad-) $2 \mathrm{~Gy}$ X-irradiation. After $48 \mathrm{~h}$, the DNA content of propidium iodide-stained nuclei was analyzed by FACSCalibur flow cytometry, as described in Materials and methods. (B) Percentage of cells in Sub-G $\mathrm{G}_{1}$. LM8 cells were treated with the indicated concentrations of SFN in the presence (black bars, $\mathrm{rad}+$ ) or absence (white bars, rad-) of $2 \mathrm{~Gy}$ X-irradiation, and the cells were analyzed by FACSCalibur flow cytometry. Data are shown as means (bars, SD) $(\mathrm{n}=3) .{ }^{*} \mathrm{P}<0.05$.
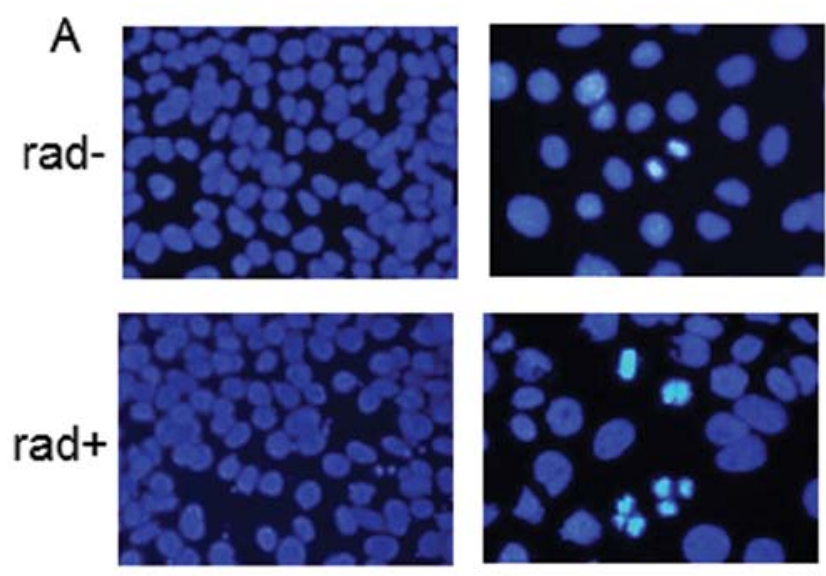

SFN-

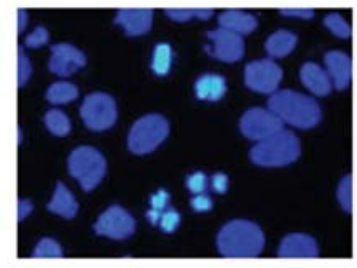

SFN+
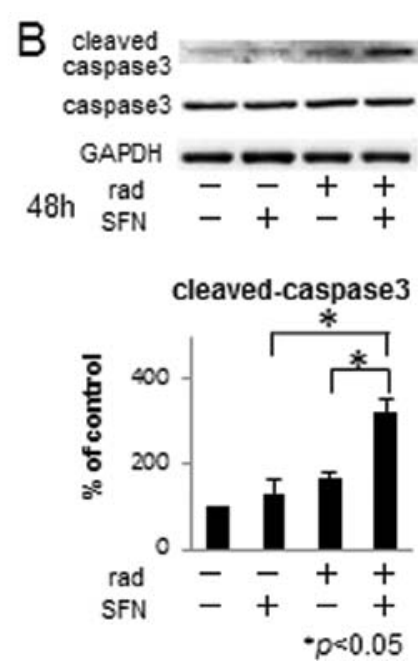

Figure 3. Combined effect of SFN and radiation on cellular apoptosis. (A) DAPI staining of LM8 cells. LM8 cells were treated with (SFN+) or without (SFN-) $20 \mu \mathrm{M}$ SFN, followed by culture in the presence (rad+) or absence (rad-) of 2 Gy X-irradiation. The cells were subsequently stained with DAPI staining and examined by fluorescence microscopy. (B) Effects of SFN and radiation on caspase-3 activation. LM8 cells were treated with (SFN+) or without (SFN-) $20 \mu \mathrm{M}$ SFN, followed by culture in the presence ( $\mathrm{rad}+$ ) or absence (rad-) of $2 \mathrm{~Gy}$ X-irradiation, and caspase-3 expression was assessed by western blotting. Subsequent incubation with an anti-GAPDH antibody was used as a loading control. Data are shown as means (bars, SD) $(n=3)$. ${ }^{*}<0.05$.

cells treated with $20 \mu \mathrm{M}$ SFN for 48 h plus 2 Gy X-irradiation for $48 \mathrm{~h}$ (Fig. 3A), and were more frequently observed than in cells treated with SFN alone. In addition, western blotting showed an increase in the amount of activated caspase- 3 in 


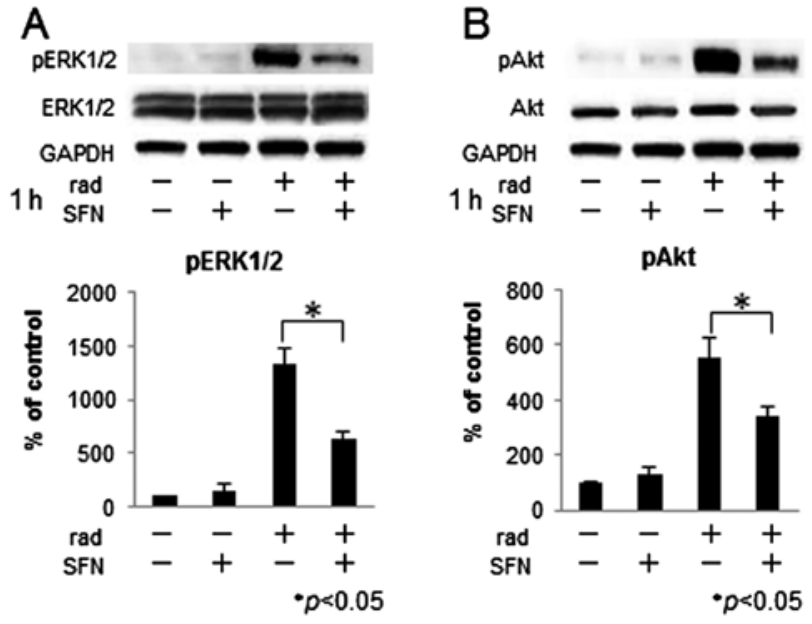

Figure 4. Effects of SFN and radiation on the phosphorylation of ERK and Akt. LM8 cells were treated with $20 \mu \mathrm{M}$ SFN and/or 2 Gy X-irradiation. After $1 \mathrm{~h}$, the expression levels of ERK, phosphorylated ERK, Akt and phosphorylated Akt proteins were assessed by western blotting. An anti-GAPDH antibody was used to confirm equal gel loading. Data are shown as means (bars, SD) $(\mathrm{n}=3) .{ }^{*} \mathrm{P}<0.05$.

cells treated with SFN plus irradiation when compared with that in cells treated with SFN alone (Fig. 3B).

Combined effects of SFN and radiation on the phosphorylation of ERK and Akt. To assess the effect of SFN and radiation on the phosphorylation of ERK and Akt, LM8 cells were treated with $20 \mu \mathrm{M}$ SFN and 2 Gy X-irradiation for $1 \mathrm{~h}$, and the expression levels of ERK, phosphorylated ERK, Akt and phosphorylated Akt protein were evaluated by western blotting (Fig. 4). We found that X-irradiation alone increased the expression of phosphorylated ERK and Akt proteins, whereas the levels of phosphorylation were lower in cells treated with both SFN and X-irradiation than in cells treated with X-irradiation alone.

\section{Discussion}

SFN, first identified in broccoli sprouts in 1992 (15), is a cancer chemopreventive agent that suppresses the growth of osteosarcoma cells and other malignant tumors. It is already being assessed in clinical trials, including a phase II trial in patients with prostate cancer. We previously reported that intraperitoneal administration of SFN significantly inhibited the growth of LM8 xenografts to less than $30 \%$ of the controls in a murine tumor model, without causing any toxicity (21).

Cell cycle arrest and apoptosis are considered to be most important among the suggested mechanisms of action of SFN. SFN has been reported to induce $\mathrm{G}_{2} / \mathrm{M}$ arrest and apoptosis in human osteosarcoma U2-OS cells (28), as well as to induce growth arrest and upregulate the expression of $\mathrm{p} 21^{\mathrm{WAF} 1 / \mathrm{CIP} 1}$ protein in a p53-independent manner in human osteosarcoma MG63 cells (14). Moreover, SFN inhibited the growth of LM8 cells i) by causing $\mathrm{G}_{2} / \mathrm{M}$-phase arrest, as shown by the appearance of cells with sub- $\mathrm{G}_{1}$ DNA content; and ii) by inducing apoptosis, as shown by the cleavage and activation of caspase-3 (21). In addition, SFN was found to inhibit the phosphorylation of Akt and ERK and to regulate apoptosis and cell proliferation. In pancreatic cancer cells, SFN was shown to induce apoptosis through the inhibition of both the PI3K/Akt and MEK/ERK pathways (22).

Following oral administration of the effective dose of SFN to rats, its maximum plasma concentration was $20 \mu \mathrm{M}$ (28). However, it was found that in humans the maximum plasma concentrations were only $2 \mu \mathrm{M}$ after oral intake of SFN-rich broccoli sprouts (29). Therefore, we studied whether or not the effects of SFN can be enhanced when combined with $\mathrm{X}$-irradiation.

Radiotherapy has long been used to treat malignant tumors. In the treatment of osteosarcoma, however, standard treatment consists of neoadjuvant chemotherapy, surgical excision and adjuvant chemotherapy. The use of radiotherapy has been limited to patients in poor general condition and those with unresectable tumors (30). In general, cells are most radiosensitive during the $\mathrm{G}_{2} / \mathrm{M}$ phase and most radioresistant during the $S$ phase $(10,11)$. Agents that induce cell cycle arrest in the $G_{2} / M$ phase have thus exhibited potent radiosensitivity in vitro and in vivo (31-34). Inhibition of WEE1 kinase has been reported to abrogate $G_{2}$ arrest and may sensitize OS cells to irradiationinduced cell death (34). In contrast, radioresistance may be due to radiation-induced activation of ERK and Akt, resulting in the dynamic and rapid adaptation of tumor cells to maintain growth and viability (12). Thus, inhibition of ERK and Akt activation may enhance the radiosensitivity of tumors $(13,35)$.

SFN has been reported to enhance the radiosensitivity of HeLa human cervical carcinoma cells in vitro and in vivo by inhibiting the repair of DNA double-strand breaks (DSB), through the inhibition of the DNA-dependent protein kinase catalytic subunit (DNA-PKcs) and RAD51 (24). Moreover, a combination of SFN and radiation was found to decrease clonogenic survival in 4 human cancer cell lines derived from head and neck squamous cell carcinomas, in which apoptosis is not regulated through Akt or the Mcl-1 protein (25).

We found that either SFN alone or radiation alone significantly and dose-dependently inhibited the growth of LM8 cells, whereas the combination of SFN and irradiation further enhanced the growth inhibitory effects. However, the precise synergistic mechanism of action of SFN and radiation is currently unknown. We, therefore, investigated the mechanisms involved when SFN and radiation were combined. Incubation of LM8 cells with SFN alone dose-dependently increased the number of cells in the $G_{2} / M$ phase and in sub- $\mathrm{G}_{1}$, as previously described $(21,27)$. Although radiation alone had no effect on the cell cycle, the combination of SFN and irradiation significantly increased the number of cells in sub- $\mathrm{G}_{1}$. These findings suggest that combination treatment may induce apoptosis more efficiently. Indeed, we found that combination treatment increased the number of cells showing nuclear fragmentation and apoptotic bodies and the expression of activated caspase-3. Thus, the SFN-induced death of LM8 cells is considered to be apoptotic.

We also studied whether the combination of SFN and radiation activates the pathway of ERK and Akt. It turned out that SFN inhibited the radiation-induced phosphorylation of ERK and Akt, suggesting that SFN enhanced the radiosensitivity of LM8 cells. These results were similar to previous findings, although the induction of apoptosis by SFN and radiation was regulated through Akt in head and 
neck squamous cell carcinoma cell lines (25). It is known that squamous cell carcinomas are considered radioreactive, whereas osteosarcomas are not. It could thus be argued that tumor cell-intrinsic properties in terms of radiosensitivity may predispose to the difference between our results and those by Kotowski et al (25).

In conclusion, we found that SFN enhanced the radiosensitivity of murine osteosarcoma LM8 cells by inducing apoptosis through G2/M-phase arrest and inhibiting ERK and Akt activation. Thus, combined treatment with SFN and radiotherapy may be useful in enhancing the antitumor effects of SFN alone. We would propose a novel therapeutic regimen for patients with osteosarcoma in which SFN and radiation are combined.

\section{Acknowledgements}

This study was supported by KAKENHI (Grant-in-Aid for Scientific Research C: 22591668 to Y.T. and H.M.).

\section{References}

1. Unni KK and Inwards CY: Dahlin's Bone Tumors, Genera Aspects and Data on 10,165 Cases. 6th edition. Lippincot Williams \& Wilkins, Philadelphia, PA, pp122-168, 2010.

2. Ferrari S, Palmerini E, Staals EL, et al: The treatment of nonmetastatic high grade osteosarcoma of the extremity: review of the Italian Rizzoli experience. Impact on the future. Cancer Treat Res 152: 275-287, 2009.

3. Gelderblom H, Jinks RC, Sydes M, et al: Survival after recurrent osteosarcoma: data from 3 European Osteosarcoma Intergroup (EOI) randomized controlled trials. Eur J Cancer 47: 895-902, 2011.

4. Zalupski MM, Rankin C, Ryan JR, et al: Adjuvant therapy of osteosarcoma - A phase II trial: Southwest Oncology Group study 9139. Cancer 100: 818-825, 2004.

5. Takeshita H, Gebhardt MC, Springfield DS, Kusuzaki K and Mankin HJ: Experimental models for the study of drug resistance in osteosarcoma: P-glycoprotein-positive, murine osteosarcoma cell lines. J Bone Joint Surg Am 78: 366-375, 1996.

6. Hirata M, Kusuzaki K, Takeshita H, Hashiguchi S, Hirasawa Y and Ashihara T: Drug resistance modification using pulsing electromagnetic field stimulation for multidrug resistant mouse osteosarcoma cell line. Anticancer Res 21: 317-320, 2001

7. Sack H: Radiation therapy and chemotherapy of primary malignant tumors of the bone. Rontgenblatter 29: 424-429, 1976 (In German)

8. Schwarz R, Bruland O, Cassoni A, Schomberg P and Bielack S: The role of radiotherapy in osteosarcoma. Cancer Treat Res 152: 147-164, 2009.

9. Ryu K, Murata H, Koto K, et al: Combined effects of bisphosphonate and radiation on osteosarcoma cells. Anticancer Res 30: 2713-2720, 2010.

10. Quiet CA, Weichselbaum RR and Grdina DJ: Variation in radiation sensitivity during the cell cycle of two human squamous cell carcinomas. Int J Radiat Oncol Biol Phys 20: 733-738, 1991.

11. Tell R, Heiden T, Granath F, Borg AL, Skog S and Lewensohn R: Comparison between radiation-induced cell cycle delay in lymphocytes and radiotherapy response in head and neck cancer. Br J Cancer 77: 643-649, 1998.

12. Yacoub A, Miller A, Caron RW, et al: Radiotherapy-induced signal transduction. Endocr Relat Cancer 13: S99-S114, 2006.

13. Marampon F, Gravina GL, Di Rocco A, et al: MEK/ERK inhibitor U0126 increases the radiosensitivity of rhabdomyosarcoma cells in vitro and in vivo by downregulating growth and DNA repair signals. Mol Cancer Ther 10: 159-168, 2011.

14. Matsui TA, Sowa Y, Yoshida T, et al: Sulforaphane enhances TRAIL-induced apoptosis through the induction of DR5 expression in human osteosarcoma cells. Carcinogenesis 27: 1768-1777, 2006.
15. Zhang Y, Talalay P, Cho CG and Posner GH: A major inducer of anticarcinogenic protective enzymes from broccoli: isolation and elucidation of structure. Proc Natl Acad Sci USA 89: 2399-2403, 1992.

16. Jackson SJT and Singletary KW: Sulforaphane: a naturally occurring mammary carcinoma mitotic inhibitor, which disrupts tubulin polymerization. Carcinogenesis 25: 219-227, 2004.

17. Gamet-Payrastre L, Li P, Lumeau S, et al: Sulforaphane, a naturally occurring isothiocyanate, induces cell cycle arrest and apoptosis in HT29 human colon cancer cells. Cancer Res 60: $1426-1433,2000$

18. Fimognari C, Nusse M, Cesari R, Iori R, Cantelli-Forti G and Hrelia P: Growth inhibition, cell-cycle arrest and apoptosis in human T-cell leukemia by the isothiocyanate sulforaphane. Carcinogenesis 23: 581-586, 2002.

19. Parnaud G, Li P, Cassar G, et al: Mechanism of sulforaphaneinduced cell cycle arrest and apoptosis in human colon cancer cells. Nutr Cancer 48: 198-206, 2004.

20. Singh SV, Herman-Antosiewicz A, Singh AV, et al: Sulforaphaneinduced $\mathrm{G} 2 / \mathrm{M}$ phase cell cycle arrest involves checkpoint kinase 2-mediated phosphorylation of cell division cycle 25C. J Biol Chem 279: 25813-25822, 2004.

21. Matsui TA, Murata H, Sakabe T, et al: Sulforaphane induces cell cycle arrest and apoptosis in murine osteosarcoma cells in vitro and inhibits tumor growth in vivo. Oncol Rep 18: 1263-1268, 2007.

22. Roy SK, Srivastava RK and Shankar S: Inhibition of PI3K/AKT and MAPK/ERK pathways causes activation of FOXO transcription factor, leading to cell cycle arrest and apoptosis in pancreatic cancer. J Mol Signal 5: 10, 2010.

23. Shankar S, Ganapathy S and Srivastava RK: Sulforaphane enhances the therapeutic potential of TRAIL in prostate cancer orthotopic model through regulation of apoptosis, metastasis, and angiogenesis. Clin Cancer Res 14: 6855-6866, 2008.

24. Yu D, Sekine-Suzuki E, Xue L, Fujimori A, Kubota N and Okayasu R: Chemopreventive agent sulforaphane enhances radiosensitivity in human tumor cells. Int J Cancer 125: 1205-1211, 2009.

25. Kotowski U, Heiduschka G, Brunner M, et al: Radiosensitization of head and neck cancer cells by the phytochemical agent sulforaphane. Strahlenther Onkol 187: 575-580, 2011.

26. Asai T, Ueda T, Itoh K, et al: Establishment and characterization of a murine osteosarcoma cell line (LM8) with high metastatic potential to the lung. Int J Cancer 76: 418-422, 1998.

27. Kim MR, Zhou L, Park BH and Kim JR: Induction of $G_{2} / M$ arrest and apoptosis by sulforaphane in human osteosarcoma U2-OS cells. Mol Med Rep 4: 929-934, 2011.

28. Hu R, Hebbar V, Kim BR, et al: In vivo pharmacokinetics and regulation of gene expression profiles by isothiocyanate sulforaphane in the rat. J Pharmacol Exp Ther 310: 263-271, 2004.

29. Ye L, Dinkova-Kostova AT, Wade KL, Zhang Y, Shapiro TA and Talalay P: Quantitative determination of dithiocarbamates in human plasma, serum, erythrocytes and urine: pharmacokinetics of broccoli sprout isothiocyanates in humans. Clin Chim Acta 316: 43-53, 2002

30. Sheplan LJ and Juliano JJ: Use of radiation therapy for patients with soft-tissue and bone sarcomas. Cleve Clin J Med 77: S27-S29, 2010

31. Zhao Y, Jiang W, Li B, et al: Artesunate enhances radiosensitivity of human non-small cell lung cancer A549 cells via increasing NO production to induce cell cycle arrest at $\mathrm{G} 2 / \mathrm{M}$ phase. Int Immunopharmacol 11: 2039-2046, 2011.

32. Yu J, Liu F, Sun M, Sun Z and Sun S: Enhancement of radiosensitivity and the potential mechanism on human esophageal carcinoma cells by tetrandrine. Cancer Biother Radiopharm 26: 437-442, 2011

33. Forde JC, Maginn EN, McNamara G, et al: Microtubuletargeting-compound PBOX-15 radiosensitizes cancer cells in vitro. Cancer Biol Ther 11: 421-428, 2011.

34. PosthumaDeBoer J, Würdinger T, Graat HCA, et al: WEE1 inhibition sensitizes osteosarcoma to radiotherapy. BMC Cancer 11: 156,2011

35. Kim IA, Bae SS, Fernandes A, et al: Selective inhibition of Ras, phosphoinositide 3 kinase, and Akt isoforms increases the radiosensitivity of human carcinoma cell lines. Cancer Res 65: 7902-7910, 2005. 